\title{
PRODUKTIVITAS HASIL TANGKAPAN BUBU PADA TERUMBU KARANG BUATAN DI PULAU PRAMUKA, KEPULAUAN SERIBU, DKI JAKARTA
}

\section{(PRODUCTIVITY OF TRAP CATCHES IN ARTIFICIAL REEF ON THE PRAMUKA ISLAND, SERIBU ISLAND, DKIJAKARTA)}

\author{
Mulyono S Baskoro', Roza Yusfiandayani ${ }^{2}$, Nur Lina Maratana Nabiu ${ }^{3}$ \\ ${ }^{1}$ Corresponding author \\ ${ }^{2}$ Departemen Pemanfaatan Sumberdaya Perikanan \\ Fakultas Perikanan dan Ilmu Kelautan, Institut Pertanian Bogor \\ E-mail :baskoro.mul@gmail.com
}

\begin{abstract}
Artificial reef made of coconut shell is an artificial habitat which is created to resemble the characteristics of natural reefs and become the alternative to improve the natural coral reefs that have been damaged. The opportunity of artificial reef utilization was researched by using experimental fishing and laboratory observe methods. The use of experimental fishing is to do the catching proses around the artificial reefs. The research was done in Angust 2013. Laboratory observe was done in September 2013 by observe the sample of fish intestines to get the data of abundance plankton from the inside of fish stomach. The results showed that 64 fishes was catches by bubu consist of 12 species. Red Breast Wrasse (Cheilinus fasciatus) from family Labridae is the dominant species. The plankton composition from the laboratory observe showed that Rhizosolenia and Leptocylindricus are the dominant plank:ton which indicate that the water is on good condition. Artificial diversity index ranged between 0,52-0,66; the uniformity index ranged between 0,17-0,21 and dominance index-0,45.
\end{abstract}

Keywords: trap, coral reef, artificial reef, plankton

\section{ABSTRAK}

Terumbu karang buatan yang terbuat dari tempurung kelapa merupakan habitat buatan yang menyerupai karakteristik terumbu karang alami yang dapat menjadi alternatif untuk memperbaiki degradasi terumbu karang alami. Peluang pemanfaatan terumbu karang buatan diteliti melalui penelitian lapang dan penelitian laboratorium. Penelitian lapang digunakan untuk melakukan proses penangkapan ikan di sekitar terumbu karang buatan. Penelitian dilakukan pada bulan Agustus 2013. Penelitian laboratorium dilakukan pada bulan September 2013 dengan meneliti sampel usus ikan untuk mendapatkan data kelimpahan plankton yang ada dalam perut ikan. Hasil penelitian lapang menunjukkan Ikan yang tertangkap dengan bubu selama penelitian di terumbu karang buatan sebanyak 64 ekor dengan 12 spesies. Spesies yang paling mendominasi adalah ikan Nori Merah (Cheilinus fasciatus) dari famili Labridae. Komposisi plankton yang terdapat pada isi perut ikan hasil tangkapan di tiga terumbu didominasi oleh Genus Rbirosoleniadan Leptocylindricus yang merupakan indikasi baik dari suatu kondisi perairan. Nilai indeks keanekaragaman (H'), nilai keseragaman (E) dan indeks dominansi $(C)$ pada hasil tangkapan terumbu karang buatan secara berturut adalah 0,52-0,66, 0,170,21 dan $0,27-0,45$

Kata kunci: bubu, terumbu karang, terumbu karang buatan, plankton

\section{PENDAHULUAN}

\subsection{Latar Belakang}

Indonesia memiliki hamparan terumbu karang yang mencakup areal sekitar $50.000 \mathrm{~km}^{2}$. Perairan Kepulauan Seribu merupakan salah satu kawasan terumbu karang yang terdapat di Indonesia yang memiliki potensi sumberdaya hayati laut yang cukup besar. Namun dengan peningkatan suhu bumi dan banyaknya penangkapan ikan dengan menggunakan alat peledak mengakibatkan banyaknya terumbu karang mengalami kerusakan. Indonesia memiliki $82 \%$ dan 590 spesies karang keras yang tersebar pada $74.748 \mathrm{~km}^{2}$ atau setara dengan $18 \%$ dari luasan terumbu karang dunia. Namun demikian, keberadaan terumbu karang juga mengalami peningkatan kerusakan dan ancaman yang tinggi setiap tahunnya. Kementerian Kelautan dan Perikanan (2009) juga menyebutkan dari sampling di 985 lokasi sebesar 31,98 persen terumbu karang berada dalam kondisi kurang 
baik. Permasalahan tersebut di-usahakan untuk dicari solusinya. Salah satunya adalah dengan membuat terumbu karang buatan atau biasa disebut artificial reef. Berbagai macam konstruksi dan material dapat digunakan dalam pembuatan terumbu karang tersebut dengan meniru beberapa karakteristik terumbu karang alam sehingga dapat memikat jenis-jenis organisme laut un-tuk hidup dan menetap serta me-ningkatkan produksi perikanan. Menurut Soedharma (1995) yang diacu dalam Pardede (2012) terumbu buatan bisa dibuat dari barang bekas (mobil, kapal, ban bekas dan bahan-bahan buatan lainnya).

Salah satu material yang pernah digunakan untuk membuat terumbu karang adalah tempurung kelapa. Terumbu karang dengan material tempurung ke-lapa tersebut sudah dipasang di perairan Pulau Pramuka sejak Maret 2012melalui penelitian yang dilakukan oleh Pardede dengan judul "Efektivitas Terumbu Buatan Berbahan Dasar Tempurung Kelapa sebagai Fish Aggregating Device di Pulau Pramuka, Kepulauan Seribu".

Sejak pemasangannya, terumbu karang tersebut dinilai memiliki peluang untuk tumbuh karang yang nantinya dapat menjadi perbaikan ekosistem terumbu karang alami. Namun dalam perkembangannya, terumbu karang tersebut perlu diteliti lebih lanjut mengenai hasil tangkapannya dan peluang penggunaan keberlanjutan dari terumbu karang bu-atan tersebut.

\subsection{Tujuan}

(1) Mengidentifikasi komposisi serta jumlah ikan yang berkumpul di sekitar terumbu karang buatan.

(2) Menganalisis isi perut ikan,indeks keanekaragaman, indeks keseragaman dan indeks dominansi hasil tangkapan.

(3) Mengidentifikasi peluang pemanfaatan terumbu karang buatan tersebut untuk kegiatan penangkapan ikan.

\section{METODOLOGI PENELITIAN}

Penelitian ini menggunakan metode experimental fishing, dimana peneliti melakukan uji coba penangkapan de-ngan alat tangkap bubu. Data yang dikumpulkan adalah data primer. Data primer yang dikumpulkan antara lain:

1) Jenis spesies ikan karang di sekitar terumbu karang buatan.

2) Komposisi dan kelimpahan plankton di sekitar terumbu karang

3) Isi perut dari ikan-ikan karang yang tertangkap

Tahap penelitian untuk pengambilan data primer ini terdiri dari penematan alat tangkap bubu tambun yang akan digunkaan untuk menangkap ikan di sekitar karang buatan dan pengambilan sampel plankton.

\subsection{Waktu dan Tempat Penelitian}

Penelitian lapangan dilakukan pada bulan Agustus 2013 di Pulau Pramuka, Kepulauan Seribu, Propinsi DKI Jakarta (Gambar 1). Penelitian laborotarium dilaksanakan pada bulan November 2013 di Laborotarium Ekobiologi dan Kon-servasi Sumberdaya Perairan Fakultas Perikanan dan Ilmu Kelautan, Institut Pertanian Bogor.

\subsection{Bahan dan Alat}

Bahan yang digunakan dalam penelitian ini adalah 64 sampel usus ikan yang diambil dari hasil ikan tangkapan terumbu karang buatan, formalin 15\%. Alat yang digunakan dalam melakukan penelitia yaitu 3 buah alat tangkap bubu tambun alat tulis, kamera, alat bedah, botol film, kertas label, kompresor, dan underwater camera. 


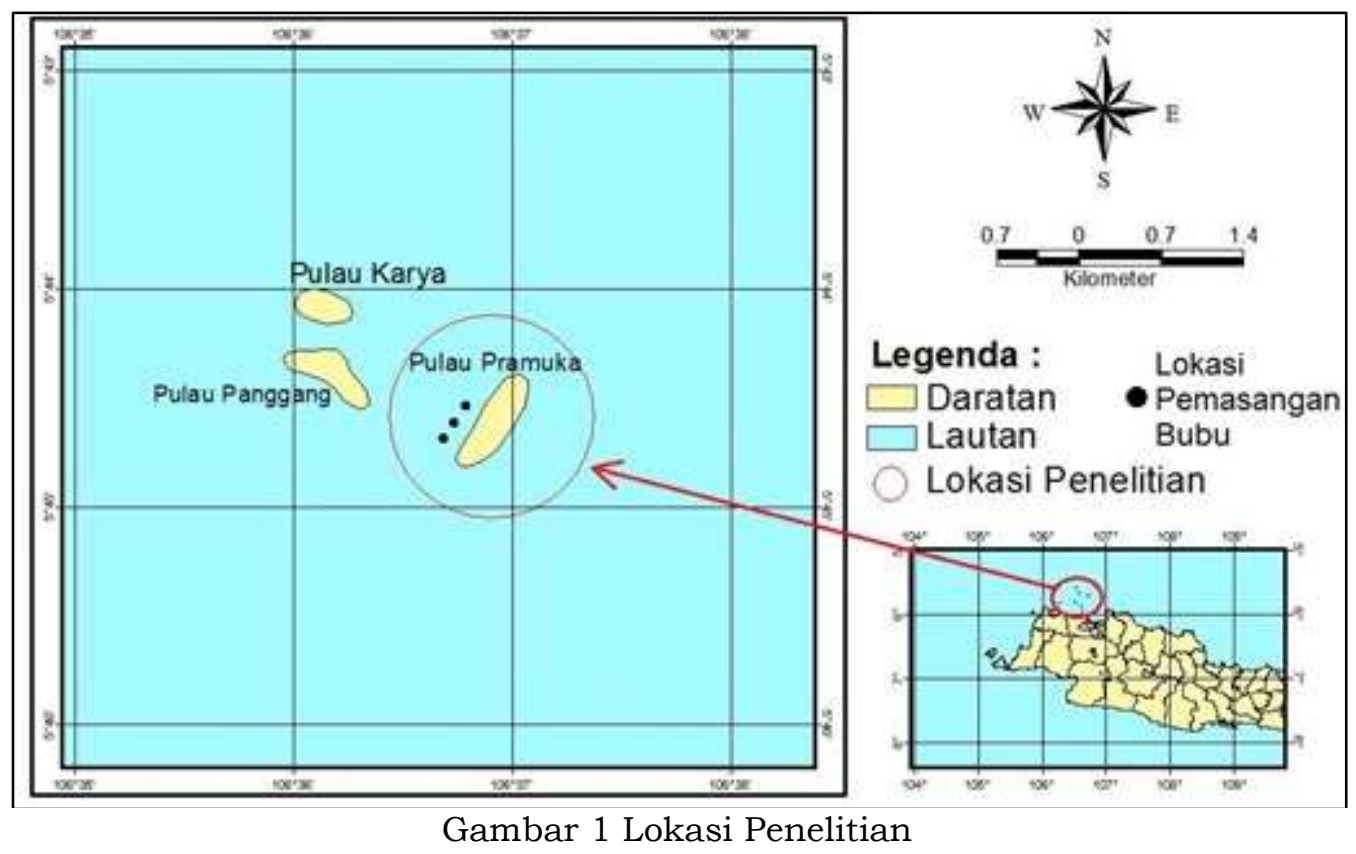

\subsection{Analisis Data}

\subsubsection{Metodologi}

Pengambilan sampel ikan di sekitar terumbu karang buatan dilakukan dengan menggunakan bubu tambun yang terbuat dari bambu dengan ukuran panjang $70 \mathrm{~cm}$, lebar $60 \mathrm{~cm}$, bukaan mulut $20 \mathrm{~cm}$ dan panjang mulut $43 \mathrm{~cm}$ (Gambar 2).Bubu tersebut dipasang di dekat terumbu karang buatan dengan jarak 3 meter, agar bubu yang dipasang tidak berpindah atau hilang karena arus, bubu ditimbun dengan menggunakan karang mati (Gambar 3).

Terumbu karang buatan yang sudah ditanam di dasar perairan sejak satu tahun sebelumnya terletak di dekat terumbu karang alami. Konstruksi dari terumbu buatan tersebut merupakan adaptasi dari terumbu karang buatan yang dibuat oleh E. Elvan Ampou, MSi yang sudah menerapkan metode Bioreeftek di Karimun Jawa sejak 2008.

Perbedaan antara bioreeftek dengan terumbu buatan yang dipasang di Pulau Pramuka terdapat pada ketebalan beton yang digunakan sebagai pemberat dan pengunci di bagian atas tempurung kelapa ditunjukkan pada Gambar 4. Masing-masing terumbu karang buatan dipasang dengan jarak 5 meter. Bubu dipasang di depan terumbu karang buatan dengan jarak 3 meter. Selama proses penelitian, bubu dioperasikan selama tiga hari. Pemasangan bubu dilaksanakan pada pagi hari dan diangkat pada pagi hari keesokan harinya.

\subsubsection{Analisis Ikan Hasil Tangkapan}

Analisis terhadap hasil tangkapan melalui identifikasi kelompok ikan bertujuan untuk melihat apakah terumbu karang buatan yang dipasang sudah bisa dikatakan sebagai terumbu karang ataukah hanya sebagai fish aggregating device.

Marasabessy (2010) menjelaskan bahwa ikan dibedakan atas tiga kelompok besar, yakni kelompok ikanikan indikator (indicator species), kelompok ikan-ikan target (target species) dan kelompok ikan-ikan lain (major group species). Ikan yang dikelompokkan ke dalam indicator species adalah jenis-jenis ikan yang dianggap berasosiasi paling kuat dengan karang. Secara umum kelompok ini terdiri dari beberapa marga (Chaetodon spp., Heniochus spp., Forcipiger spp., dan Hemitaurichthys sp.) yang masuk dalam suku Chaetodontidae. Ikan kea-kea umumnya hidup sendirisendiri atau berpasang-pasangan dan selalu dijumpai dalam kelompokkelompok kecil. Biasanya berenangrenang di antara bongkahan dan kolonikoloni karang, memangsa polip-polip pembentuk karang. Dengan kebiasaan hidup sendiri( solitaire) memungkinkan kelompok ikan tersebut sangat mudah dihitung satu demi satu atau sepasang demi sepasang (actual account). 


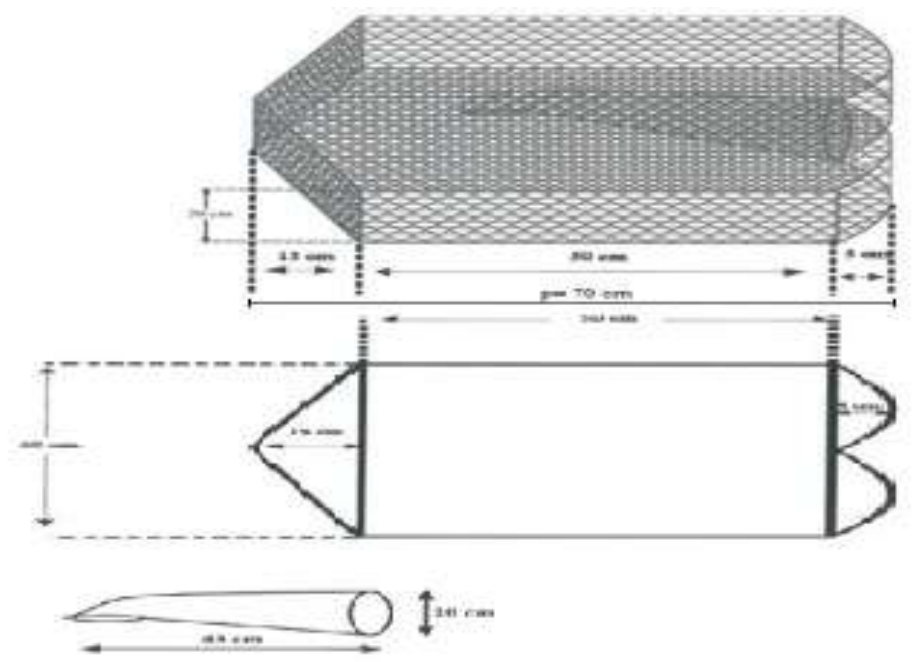

Gambar 2 Konstruksi bubu tambunSumber: Ramadan (2011)
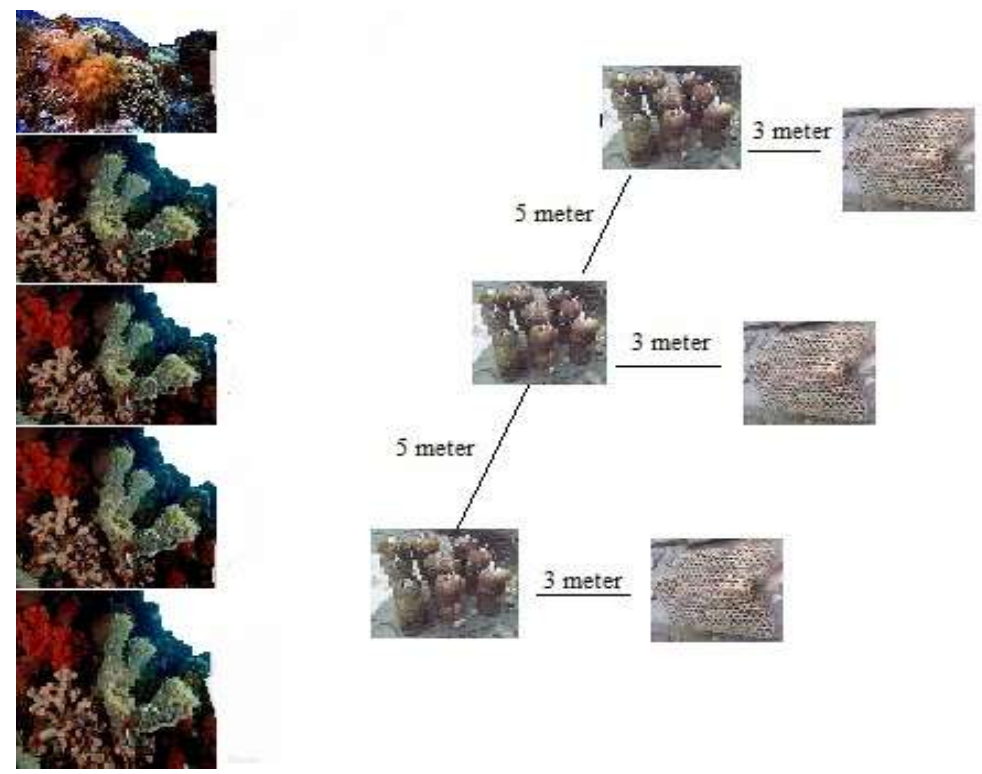

Gambar 3 Ilustrasi pemasangan bubu

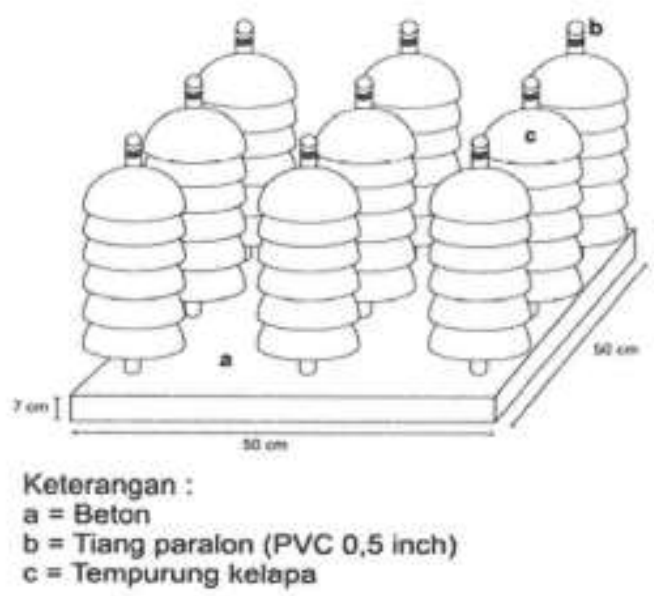

Gambar 4 Konstruksi terumbu buatan 
Kelompok ikan target (target species) meliputi ikan-ikan konsumsi dan ekonomis penting yang berasosiasi dengan karang, termasuk di antaranya adalah kakap (Lutjanus sp) dari suku Lutjanidae, kerapu (Epinephelus sp) dari suku Serranidae, baronang (Siganus sp) dari suku Siganidae, serta beberapa jenis yang selalu diburu nelayan dengan menggunakan berbagai jenis alat tangkap. Umumnya ikan-ikan target hidup secara soliter sehingga mudah dihitung satu demi satu. Ada beberapa jenis ikan target yang dijumpai dalam kelompok besar misalnya ikan ekor kuning (Caesio sp.) suku Caesionidae. Ikan-ikan target yang dijumpai dalam kelompok besar biasanya dihitung dengan menaksir jumlah ikan seperti yang dilakukan terhadap ikan-ikan majorgroup. Jenisjenis ikan yang dikelompokkan sebagai major group meliputi semua ikan yang tidak termasuk dalam kedua kelompok diatas. Umumnya hidup dalam kelompok besar (schooling fish), misalnya ikan Betok (Chromis ternatensis), C. margaritifer dan Dascillusreticulatus (Pomacentridae), beberapa jenis dari suku Pomacanthidae, Serranidae, Acanthuridae dan Labridae. Ikan-ikan yang tergabung dalam kelom-pok major fish umumnya berukuran kecil-kecil dan hanya sebagian kecil berpotensi sebagai ikan hias.

\subsubsection{Analisis Isi Usus Ikan}

Ikan-ikan yang tertangkap diidentifikasi dengan mengacu buku identifikasi: Taksonomi dan Kunci Identifikasi Ikan Jilid 1 dan Jilid 2 (Saanin, 1984), kemudian ikan dibedah dengan cara menggunting bagian perut ikan dimulai dari anus hingga ke tutup insang, kemudian ususnya diambil secara per-lahan. Usus dan lambung ikan dimasukkan ke dalam botol sampel dan diawetkan dengan menggunakan formalin $15 \%$ untuk perhitungan analisis makanan yang dilakukan di laboratorium. Botol diberi label yang ditempelkan di dinding luar botol sampel. Label tersebut dituliskan: nomor stasiun, tanggal dan waktu pengambilan serta nama ikan.

Sampel usus ikan satu per satu dikeluarkan dari botol sampel dan dibersihkan dari formalin. Kemudian isi usus dipisahkan dari daging usus dengan cara menggunting daging usus dan diambil isinya, isi usus diencerkan de-ngan aquades sebanyak $3 \mathrm{ml}$ dan diaduk-aduk sehingga tidak terjadi penumpukan isi usus di suatu wilayah. Satu tetes pengenceran diambil kemudian diamati dengan menggunakan mikroskop binokuler dengan ukuran 10x10 dan pengambilan lima lapang pandang dalam satu kali pengamatan. Pengamatan diulang sebanyak tiga kali sehingga akan didapatkan data dari 15 lapang pandang. Apabila jenis organisme yang didapat adalah plankton, maka dapat diidentifikasi dengan mengacu pada buku identifikasi: Illustration of the Marine Plankton of Japan (Yamaji, 1976).

\subsubsection{Kelimpahan Plankton}

Kelimpahan plankton digunakan untuk mengetahui jumlah kemungkinan plankton yang terdapat dalam usus ikan yang sudah diamati. isi usus dipisahkan dari daging usus dengan cara menekan daging usus sampai semua isinya keluar, diencerkan dengan aquades sebanyak 3 $\mathrm{ml}$ dan diaduk-aduk sehingga tidak terjadi penumpukan isi usus di suatu wilayah. Satu tetes pengenceran diambil kemudian diamati menggunakan mikroskop binokuler dengan perbesaran 10x10 dan pengambilan lima lapang pandang dalam satu kali pengamatan. Pengamatan diulang sebanyak tiga kali sehingga akan didapatkan data dari 15 lapang pandang. Apabila jenis organisme yang didapat adalah plankton, maka dapat diidentifikasi dengan mengacu pada buku identifikasi: Ilustration of the Marine Plankton of Japan (Yamaji, 1976). Metode menghitung jumlah kelimpahannya dengan rumus sebagai berikut ini :

$$
N=\frac{V b}{V i} x n
$$

Keterangan : $\mathrm{N}=$ jumlah kelimpahan organisme dalam usus ikan

$$
\begin{aligned}
\mathrm{V}_{\mathrm{b}}= & \text { volume pengeceran } \\
\mathrm{Vi}= & \text { volume satu tetes contoh } \\
\mathrm{n}= & \text { banyaknya organisme } \\
& \text { dalam satu tetes contoh }
\end{aligned}
$$




\subsubsection{Trofik Level Hasil Tangkapan}

Trofik level adalah posisi suatu organisme dalam jaring makanan (Froese dan Pauly (2000). Stergiou et al. (2007) menyebutkan bahwa trofik level menunjukkan keberadaan ikan dan organisme lainnya yang masing-masig berperan dalam jaring makanan. Trofik level suatu jenis ikan ditentukan berdasarkan komposisi makanan dan trofik level masing-masing fraksi makanannya (food items) yang diperoleh dari hasil analisis aisi perut (Froese dan Pauly 2000). Deskripsi kebiasaan makan dilakukan untuk mengestimasi trofik level yang meliputi tiga kasus, yaitu sebagai berikut:

Kasus 1: semua makanan adalah tumbuhan atau detritus, maka trofik levelnya $=2$ dan kuadrat frekuensi kejadiannya $=0$.

Kasus 2: hanya ada satu makanan dan tidak ada satupun tumbuhanatau detritus, maka trofik levelnya $=1+$ trofik level makanan dan kuadrat frekuensi kejadiannya $=$ kuadrat frekuensi kejadian makanan.

Kasus 3: terdapat beberapa macam makanan dan paling sedikit bukan tumbuhan atau detritus, makatrofik levelnya ditentukan dengan persamaan:

$$
\overline{\text { Troflk level }}=\frac{\sum_{i=1}^{p} \text { Pi } x \text { Trofik } i}{\sum P i}
$$

Keterangan:

Trofik level : Rata-rata trofik level

$\mathrm{Pi} \quad$ : fraksi makanan ke-i

Trofik $k_{\mathrm{i}} \quad$ : Trofik level makanan ke-i

Ristiani (2012) menjelaskan bahwa trofik level ini mengacu pada konvensi Internasional Program Biologi pada tahun 60-an yang menyepakati produser primer (fitoplankton) dan detrius (termasuk bakteri) dikategorikan dalam trofik level satu (TL 1), sementara zooplankton dalam trofik level dua (TL 2).

\subsubsection{Indeks Keanekaragaman ( $\left.\mathrm{H}^{\prime}\right)$}

Indeks keanekaragaman ( $\left.\mathrm{H}^{\prime}\right)$ adalah ikuran kekayaan jenis komunitas ikan karang dilihat dari jumlah spesies dalam suatu kawasan berikut jumlah individu dalam setiap spesiesnya. Tingginya keanekaragaman menunjukkan sutu ekosistem yang seimbang dan memberikan peranan yang besar untuk menjaga keseimbangan terhadap kejadian yang merusak ekosistem dan suatu spesies dibandingkan dengan spesies lain. Nilai dari indeks keanekaragaman $\left(\mathrm{H}^{\prime}\right)$ menunjukkan ditribusi individu-individu antar spesies ikan karang dalam komunitasnya. Semakin tinggi nilai indeks keanekaragaman, menunjukkan keseimbangan makin baik. Kreb (1985) diacu dalam Yusfiandayani (2004) menjelaskan bahwa untuk menghitung indeks keanekaragaman digunakan indeks Shanon-Wiener:

$$
H^{\prime}=-\sum_{i=1}^{s}(p i \ln \mathrm{pi})
$$

Keterangan:

$\begin{array}{ll}H^{\prime} & : \text { Indeks keanekaragamn } \\ s & : \text { jumlah spesies ikan karang } \\ \text { pi } & : \text { proporsi jumlah ikan karang } \\ & \text { spesies ke-i terhadap } \\ & \text { jumlah total ikan } \\ & \text { karang pada stasiun } \\ & \text { pengamatan. } \\ & \text { Kisaran indeks keanekaragaman }\end{array}$
diklasifikasikan untuk ikan karang adalah:

$H^{\prime} \leq 3,2$ : keanekargaman kecil, tekanan lingkungan kuat

$3,2<H^{\prime} \leq 9,9$ : keanekaragaman sedang, tekanan lingkungan sedang

$H^{\prime} \leq 9,9$ : keanekaragamn tinggi, terjadi keseimbangan ekosistem.

2.3.7. Indeks Keseragaman (E)

Untuk mengukur keseimbangan digunakan indeks keseragaman (E), yaitu ukuran kesamaan jumlah individu antar spesies dalam komunitas (Kreb 1985 diacu dalam Yusfiandayani 2004).

Keterangan :

$$
E=\frac{H^{\prime}}{H^{\prime} \max }
$$

$$
\begin{array}{ll}
E & : \text { Indeks keseragaman } \\
H^{\prime} \max & : \text { Indeks keseragaman } \\
& \text { maksimum ln } \mathrm{s} \\
\mathrm{s} & : \text { jumlah spesies dalam } \\
& \text { komunitas }
\end{array}
$$

Nilai indeks keseragaman antara 0-1 dengan kriteria sebagai berikut:

$0<E \leq 0,5 \quad$ : keseragamn kecil, 


$$
\begin{gathered}
0,5<E \leq 0,75: \begin{array}{c}
\text { komunitas tekanan } \\
\text { keseragaman sedang, } \\
\text { komunitas labil }
\end{array} \\
0,75<E \leq 1 \quad \begin{array}{c}
\text { keseragaman tinggi, } \\
\text { komunitas stabil }
\end{array}
\end{gathered}
$$

Dari kisaran nilai ini terlihat semakin kecil indeks keseragaman $(E)$, semakin kecil pula keseragaman populasi yang berarti penyebaran jumlah individu setiap jenis tidak sama dan ada kecenderungan populasi didominasi oleh jenis organisme tertentu. Begitu pula sebaliknya, semakin besar nilai $E$ maka populasi tersebut menunjukkan keseragaman yang tinggi, yaitu jumlah individu setiap jenis dapat dikatakan sama atau tidak jauh berbeda.

\subsubsection{Indeks Dominasi (C)}

Apabila indeks dominasi suatu komunitas tinggi maka komunitas tersebut cenderung labil. Rumus yang digunakan sebagai berikut (Kreb, 1985 diacu dalam Yusfiandayani, 2004):

Keterangan:

$$
C=\sum_{i=1}^{s} p i^{2}
$$

$C$ : Indeks dominansi;

$\mathrm{Pi} \quad$ : Proporsi jumlah ikan karang spesies ke-i terhadap jumlah total ikan karang pada stasiun pengamatan.

Indeks dominansi berkisar antara 0-1, apabila nilai mendekati 1 maka ada kecenderungan satu individu yang mendominasi lainnya. Kisaran indeks diklasifikasikan sebagai berikut:

$0<C \leq 0,5 \quad$ : Dominansi rendah;

$0,5<C \leq 0,75$ : Dominansi sedang; dan

$0,75<E \leq 1 \quad$ : Dominansi tinggi.

\section{HASIL DAN PEMBAHASAN}

\subsection{Pemasangan Bubu Tambun}

Proses awal dari penelitian ini adalah pemasangan bubu tambun sebanyak tiga buah bubu yang digunakan untuk menangkap ikan di sekitar terumbu karang buatan. Penelitian ini merupakan kegiatan monitoring dari penelitian sebelumnya. Terumbu karang buatan yangterbuat dari tempurung kelapa tersebut sudah dipasang di lokasi sejak Maret 2012 melalui penelitian yang dilakukan olehPardede.Saat pengamatan terakhir, kondisi terumbu karang buatan tersebutmasih cukup baik bahkan karang-karang sudah mulai tumbuh di beberapa substrat tempurung kelapa. Letak lokasi terumbu karang yaitu $05^{045045,5^{0}}$ LS; $106^{036038^{\circ}}$ BT dengan kedalaman 23 meter dan memiliki dasar berpasir.

Pemasangan tiga bubu tambun dimulai pagi hari pada tanggal 27 Agustus 2013 dengan kondisi arus dan gelombang yang cukup baik. Sebelum bubu dipasang, bubu telah direndam selama satu minggu di dekat lokasi terumbu. Pemasangan bubu tambun dilakukan oleh dua orang nelayan. Satu orang berada di bawah kapal dan satu orang lagi berada di atas kapal. Jarak pemasangan bubu tambun dari terumbu buatan sekitar 3 meter. Pemasangan bubu ini dilakukan rutin selama tiga hari dengan waktu pemasangan yang hampir sama dengan waktu pemasangan di hari sebelumnya.

\subsection{Hasil Tangkapan Bubu Tambun}

Hasil tangkapan ikan di terumbu karang buatan dengan menggunakan tiga alat tangkap bubu selama penelitian sebanyak 64 ekor dengan 12 spesies. Spesies yang paling mendominasi adalah ikan Nori Merah (Cheilinus fasciatus) dari famili Labridae sebanyak 23\% dari hasil tangkapan yaitu 15 ekor ikan. Spesies kedua yang mendominasi hasil tangkapan adalah Sersan Mayor (Abudefduf bengalensi) dari famili Pomacentridae sebanyak 10 ekor ikan dan Betok Susu (Dischitodus perspicillatus) dari famili Anabantidae yang merupakan spesies dominan ketiga dari hasil tangkapan juga sebanyak 10 ekor ikan ditujukan pada Gambar 5. 


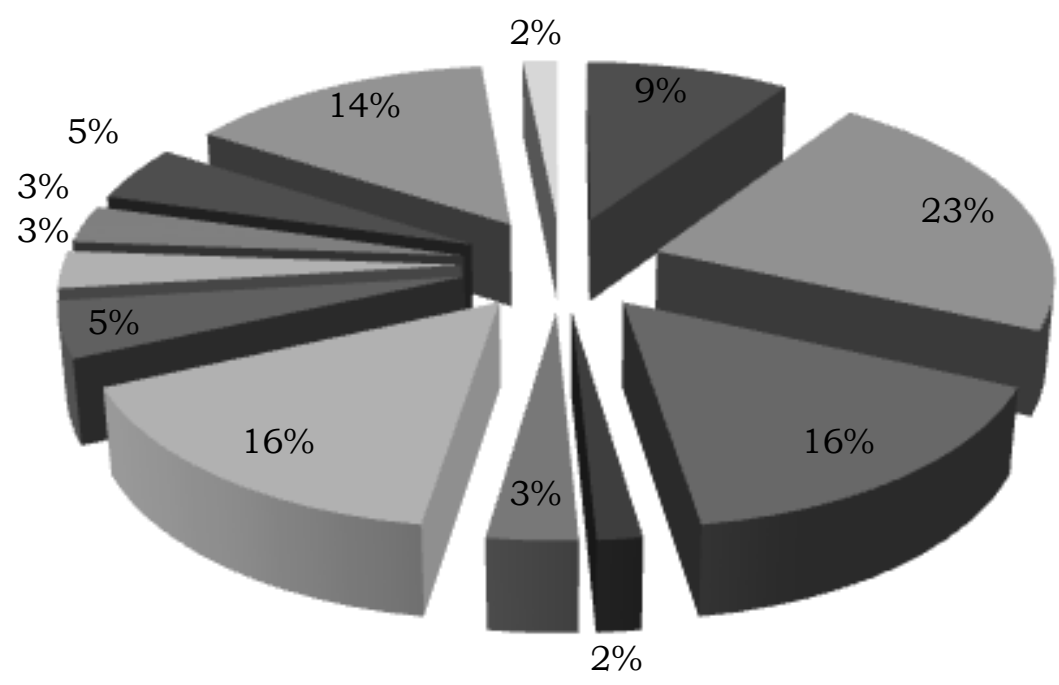

- Dischitodus

pseudochrysopoecilus

- Cheilinus fasciatus

- Abudefduf bengalensis

- Lethrinus obsoletus

- Scolopsis lineata

- Dischitodus perspicillatus

- Plectropomus leopardus

Chaetodontoplus mesoleucus

Epinephelus tauvina

Siganus sp

- Scarus niger

Rhinecanthus aculeatus

Gambar 5 Komposisi hasil tangkapan bubu tambun berdasarkan spesies

Hasil tangkapan bubu menunjukkan bahwa terdapat ikan-ikan dari tiga pengelompokan ikan karang. Ikan kea-kea ditemukan pada hasil tangkapan sebagai ikan yang masuk dalam indicatorspecies. Menurut Marabessy (2010), ikan kea-kea termasuk ikan yang berasosiasi paling kuat dengan karang, biasanya berenangrenang diantara bog-kahan dan kolonikoloni karang, me-mangsa polip-polip pembentuk karang. Ikan kerapu yang didapat dari hasil tangkapan merupakan ikan yang men-jadi target species, sementara mayoritas ikan yang tertangkap merupakan ikan yang masuk ke dalam kategori major species, seperti ikan betok dan ikan nori merah. Hal inimenunjukkan bahwa terumbu karang buatan yang terpasang sudah mulai menjadi tempat asosiasi bagi ikan-ikan di sekitarnya sehingga terumbu karang buatan tersebut diperkirakan sudah menyerupai habitat terumbu karang alami.

Hasil tangkapan bubu mengalami fluktuasi di setiap tripnya. Hal tersebut dikarenakan cuaca yang berubah-ubah sehingga hampir tidak mendukung proses penangkapan seperti yang terjadi pada trip di hari pertama, dimana gelombang dan arus tergolong cukup kuat.
Jumlah dan komposisi ikan terbanyak didapat saat penangkapan di hari kedua. Namun variasi spesies pada penangkapan hari ketiga lebih banyak jika dibandingkan hari sebelumnya, seperti kerapu lumpur yang memiliki nilai ekonomis cukup tinggi. Jumlah hasil tangkapan setiap bubu pada setiap penangkapan disajikan pada Gambar 6 .

Hasil tangkapan bubu yang dipasang di terumbu pertama lebih mendominasi dalam setiap proses penang-kapan, diduga karena posisi terumbu karang yang lebih dekat dengan terumbu karang alami. Pada hari pertama, hasil tangkapan tidak sebanyak dua hari ber-ikutnya. Hal itu kemungkinan di-sebabkan oleh cuaca di hari pertama yang kurang mendukung untuk melakukan proses penangkapan.

\subsection{Analisis Kelimpahan Plankton pada Usus Ikan}

Analisis plankton pada usus ikan dimulai pada bulan September selama dua minggu. Analisis tersebut digunakan untuk melihat kelimpahan plankton yang ada di dalam usus ikan. Berdasarkan hasil pengamatan, kelimpahan plankton tertinggi pada hasil tangkapan bubu pertama saat penangkapan di hari kedua sebanyak 5.640 plankton/ml Gambar 7 . Plankton terbanyak yang terlihat adalah 
plankton dari genus Rhizosolenia. Genusyang ditemukan adalah genus Leptocylindricus, genus Coscinodiscus, dan genus Pleurosigma, Sagitta. Sementara kelimpahan plankton terkecil terdapat pada hasil tangkapan bubu kedua saat penangkapan hari pertama dengan kelimpahan plankton sebanyak 1860 plankton $/ \mathrm{ml}$.

Plankton genus Rhizosolenia merupakan jenis plankton yang bisa ditemukan di perairan laut dan payau, terutama di perairan yang memiliki suhu hangat (Microbewiki, 2010). Hasil pengamatan dari usus, plankton Rhizosolenia juga ditemukan hampir di semua peng-amatan. Perbandingan plankton hasil pengamatan usus ikan dapat dilihat pada Gambar 8.

Plankton Rhizosolenia mendominasi hasil pengamatan dengan persentase lebih dari 50 persen, sementara Leptocylindricus $s p$. menjadi plankton yang mendominasi kedua dengan persentase sebesar 5 persen ditunjukan pada Gambar 9. Menurut Microbewiki (2010) dan red-tide (1999), Rhizosolenia dan Leptocylindricus bisa menjadi salah satu indikasi kondisi perairan. Semakin banyak Rhizosolenia dan Leptocylindricus yang ditemukan, maka semakin baik suatu perairan, contohnya Leptocylindricus akan menjadi racun apabila kondisi oksigen di sekitarnya menurun. Hal tersebut menunjukkan bahwa kondisi perairan tempat terumbu karang dipasang masih dalam kondisi yang baik dan tentunyaakan berpengaruh baik pada kondisi ikan dengan lingkungan yang memiliki kadar oksigen yang cukup.

Tabel 1 menunjukkan bahwa pada lima ikan yang paling dominan tertangkap semuanya ditemukan plankton genus Rhizosolenia. Genus Leptocylindricus hanya ditemukan pada spesies Nori Merah, Sersan Mayor danBetok. Genus Sagitta ditemukan pada spesies Sersan Mayor, Betok Susu dan Betok. Spesies Nori Merah, Sersan Mayor dan Betok Susu ditemukan memiliki genus Pleurosigma di dalam ususnya.

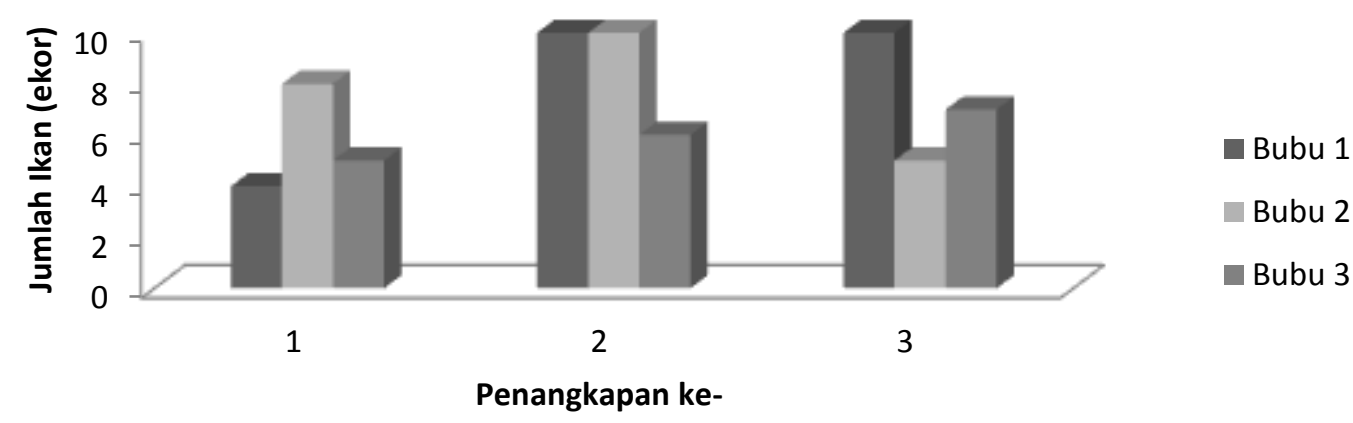

Gambar 6 Jumlah hasil tangkapan bubu per stasiun terumbu

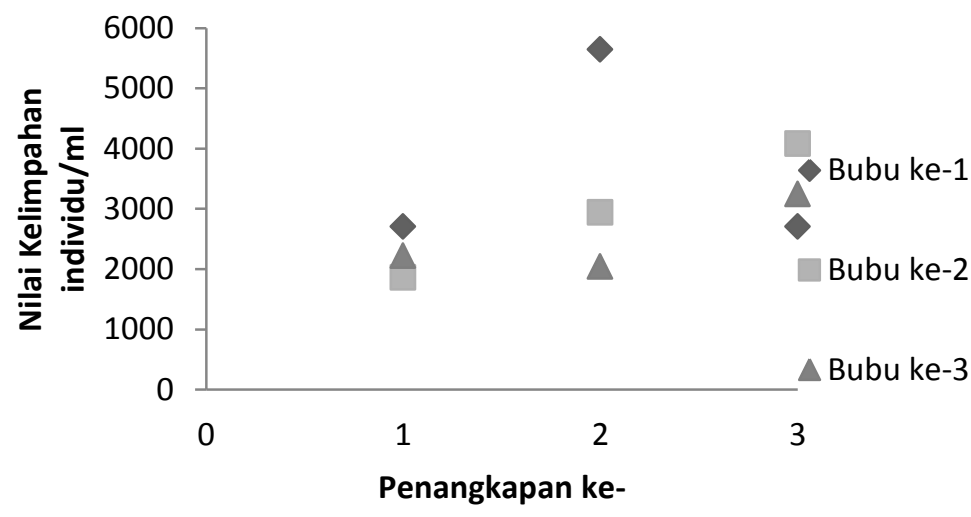

Gambar 7 Nilai kelimpahan plankton pada usus ikan 


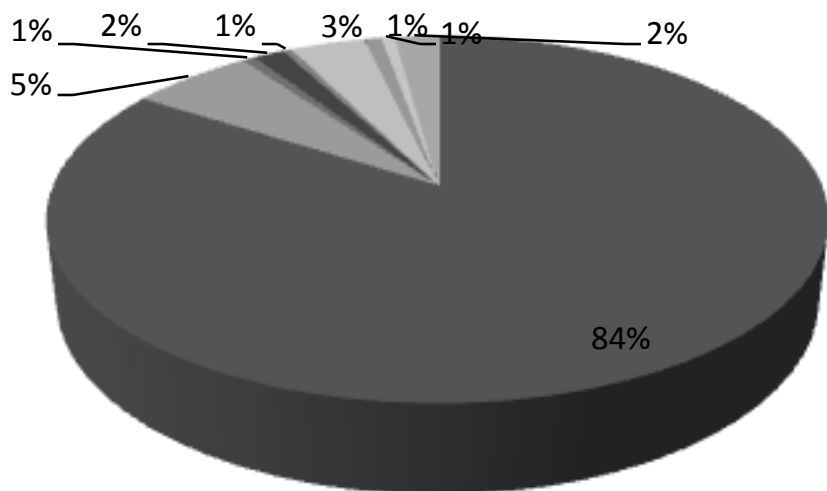
- Rhizosolenia
- Leptocylindricus
- Coscinodiscus
- Pleurosigma
Paralia
Sagitta
Thalassiosira
Gymnodinium
Lain-lain

Gambar 8 Perbandingan plankton hasil pengamatan usus ikan berdasarkan genus

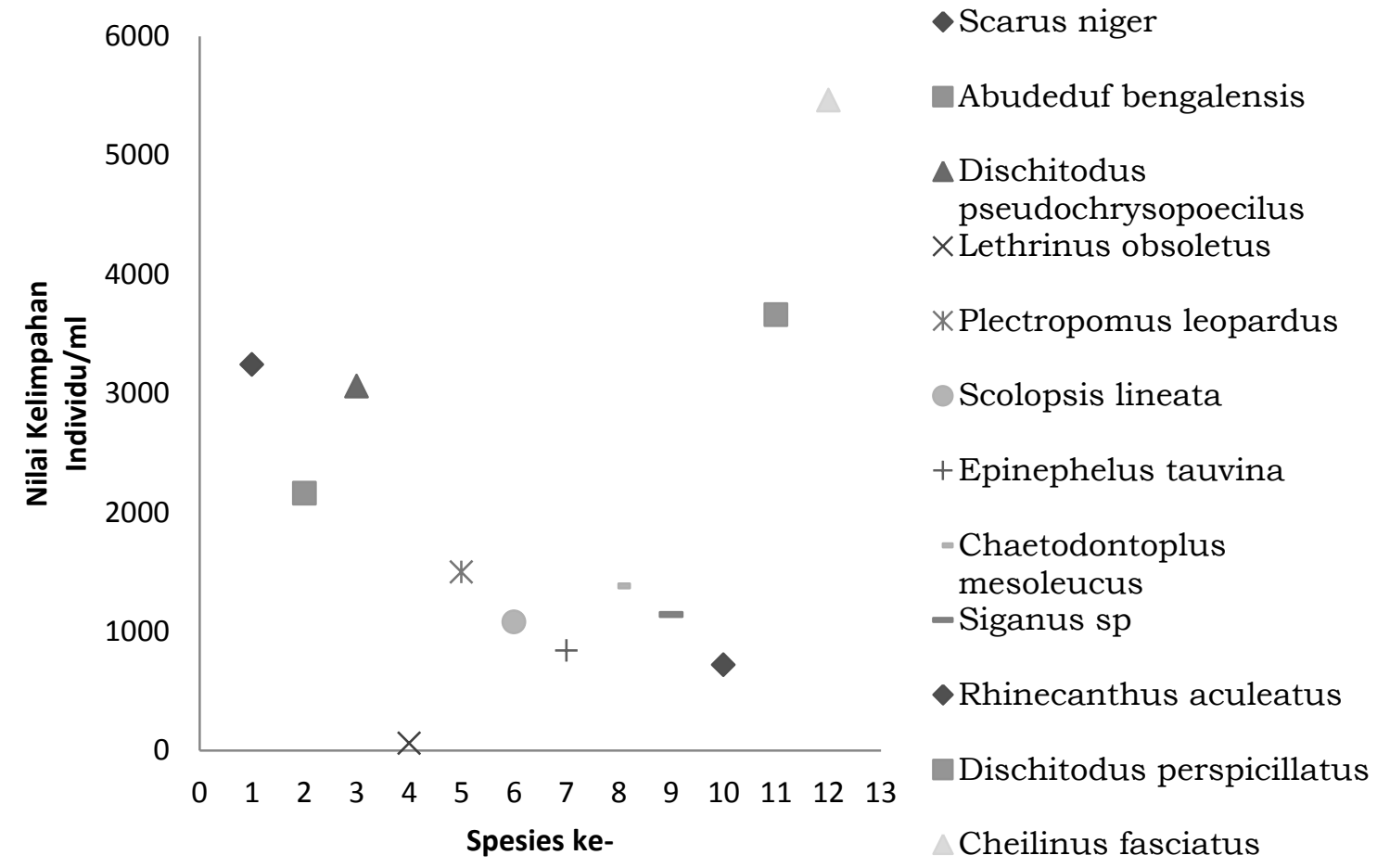

Gambar 9 Nilai kelimpahan plankton per spesies ikan hasil tangkapan 
Tabel 1Komposisi plankton pada isi perut ikan

\begin{tabular}{lccccc}
\hline \multirow{2}{*}{ Genus } & \multicolumn{5}{c}{ Spesies ikan } \\
\cline { 2 - 5 } Plankton & Nori & Sersan & Betok & Kakak & \\
& Merah & Mayor & Susu & Tua & Betok \\
& (Cheilinus & (Abudefduf & (Dischitodus & Scarus & 'Dischitodus \\
& fasciatus) & bengalensis) & perspicillatus) & niger) & lochrysopoecilus) \\
solenia & $\sqrt{ }$ & $\sqrt{ }$ & $\sqrt{ }$ & $\sqrt{ }$ & $\sqrt{ }$ \\
cylindricus & $\sqrt{ }$ & $\sqrt{ }$ & - & - & $\sqrt{ }$ \\
ta & - & $\sqrt{ }$ & $\sqrt{ }$ & $\sqrt{ }$ & \\
osigma & $\sqrt{ }$ & & $\sqrt{ }$ & & - \\
\end{tabular}

\subsection{Indeks Keanekaragaman ( $\left.\mathbf{H}^{\prime}\right)$, Keseragaman (E) dan Dominansi Ikan Hasil Tangkapan pada Terumbu Karang buatan}

Hasil tangkapan ikan dengan jumlah trip tiga kali memiliki indeks keanekaragaman berkisar antara 0,520,66 . Indeks tersebut menunjukkan asumsi bahwa keanekaragaman kecil, tekanan lingkungan kuat. Sementara indeks keseragaman berkisar antara 0,17-0,21, ini berarti keseragaman ikan di sekitar terumbu karang kecil dengan penyebaran jumlah individu setiap jenis tidak sama.Indeks dominansi berkisar 0,27-0,45. Hal tersebut menunjukkan bahwa dominansi ikan hasil tangkapan di sekitar terumbu karang buatan rendah. Perbandingan indeks tersebut dapat dilihat pada Gambar 10.

Apabila dilihat dari hasil perhitungan, ketiga indeks tersebut menujukkan hasil keanekaragaman, keseragaman, dan dominansi yang rendah. Tingkat keanekaragaman yang rendah menunjukkan tingkat keseimbangan populasi yang rendah, tingkat ke-seragaman dan dominansi yang rendah menunjukkan kesamaan jumlah individu antar spesies dalam komunitas rendah, ini berarti dalam hasil tangkapan tidak ada spesies ikan yang tertangkap dalam jumlah yang dominan, setiap spesies tertangkap memiliki jumlah yang hampir sama. Hal tersebut kemungkinan disebabkan oleh kondisi perairan yang kurang mendukung pada saat me-lakukan proses pemasangan dan penangkapan.

\section{KESIMPULAN DAN SARAN}

\subsection{Kesimpulan}

Kesimpulan yang dapat diambil dari penelitian ini sebagai berikut ini :

1. Ikan yang tertangkap dengan bubu selama penelitian di terumbu karang buatan sebanyak 64 ekor dengan 12 spesies. Spesies yang paling mendominasi adalah ikan Nori Merah (Cheilinus fasciatus) dari famili Labridae.

2. Komposisi plankton yang terdapat pada isi perut ikan hasil tangkapan di tiga terumbu didominasi oleh Genus Rhizosolenia dan Leptocylindricus yang merupakan indikasi kondisi perairan. Nilai indeks keaneka-ragaman $\left(\mathrm{H}^{\prime}\right)$, nilai keseragaman (E) dan indeks dominansi (C) pada hasil tangkapan terumbu karang buatan secara berturut adalah $0,52-0,66,0,17-0,21$ dan 0,27-0,45.

3. Terumbu buatan yang digunakan dalam penelitian memiliki tingkat efisien sebagai fish aggreating device yang cukup baik dan memiliki peluang positif untuk dapat menjadi salah satu alternatif terumbu karang yang sudah mengalami degradasi.

\subsection{Saran}

1. Perlu diadakan penelitian lebih lanjut dengan penggunaan unit terumbu karang buatan yang lebih banyak dan penentuan lokasi yang lebih baik serta kedalaman yang berbeda sehingga dapat menjadi 
penguat bukti bahwa terumbu karang buatan dapat menjadi alternatif terumbu karang alami.

2. Diperlukannya penelitian lebih lanjut tentang komposisi plankton dan perifiton yang terdapat pada terumbu karang buatan.

\section{DAFTAR PUSTAKA}

Abundance. Third Edition. Harper \& Row Publisher. New York.

Marabessy MD. 2010. Keanekaragaman Jenis Ikan Karang di Perairan Pesisir Biak Timur Papua. [Jurnal]. Pusat Penelitian Oseanografi: LIPI.

Microbewiki. 2010. Rhizosolenia. [Internet]. [diunduh 2013 Okt 26]. Tersedia pada: http// microbewiki.com

Pardede FM. 2012. Efektivitas Terumbu Buatan Berbahan Dasar Tempurung Kelapa Sebagai Fish Aggregating Device Di Pulau Pramuka Kepulauan Seribu. [Skripsi]. Bogor (ID): Institut Pertanian Bogor.

Ramadan ANS. 2011. Uji Coba Tutupan Ijuk dan Goni pada Pengoperasian Bubu Tambun di Perairan Kepulauan Seribu. [Skripsi]. Bogor (ID): Institut Pertanian Bogor.

Red-tide. $1999 . \quad$ Leptocylindricus. [Internet]. [diunduh 2013 Okt 27]. Tersedia pada: http//red-tide.org

Ristiani. 2012. Dampak Penangkapan Ikan Terhadap Keseimbangan Trofik Level pada Habitat Lamun di Kepulauan Seribu, Provinsi DKI Jakarta. [Skripsi]. Bogor (ID); Institut Pertanian Bogor.

Saanin H. 1984. Taksonomi dan Kunci Identifikasi Ikan Jilid 1 dan Jilid 2. Bogor (ID): Penerbit Djambatan.

Soedharma D. 1995. Studi Komunitas Perifiton dan Komunitas Ikan pada Terumbu Ban dan Bambu di Teluk Lampung, Prosiding Seminar Hasil Penelitian Ilmu Kelautan. IPB. Hal 99-113.

Stergiou KI, Moutopulus DK, Casal HJA dan Erzini K. 2007. Trophic Signatures of Small-Scale Fishing Gears: Implications for Conservation and Management.
Marine Ecology Progress Series. No. 33:117-128.

Yamaji I. 1976. Ilustrations of The Marine Plankton of Japan. Osaka (JPN): Hoikusha Publishing. Co. LTD.

Yusfiandayani R. 2004. Studi Tentang Mekanisme Berkumpulnya Ikan Pelagis Kecil di Sekitar Rumpon dan Pengembangan Perikanan di Perairan Pasauran, Propinsi Banten. [Disertasi]. Bogor (ID): Institut Pertanian Bogor. 